\title{
STUDI LITERATUR Candida albicans PADA AIR BAK TOILET
}

\author{
Hasmiati $^{1)}$, Mujahidah Basarang ${ }^{1)}$, Nurhidayat ${ }^{1)}$ \\ 1) Prodi D III Teknologi Laboratorium Medis Politeknik Kesehatan Muhammadiyah Makassar \\ Alamat Korespondensi: hasmiati.taho@gmail.com
}

\begin{abstract}
Abstrak
Toilet adalah sarana sanitasi yang paling vital. Kebersihan toilet dapat dijadikan ukuran terhadap kualitas manajemen sanitasi di suatu tempat. Parameter kebersihan toilet yang paling utama dapat dilihat dari frekuensi menguras atau pembersihan air baknya, sanitasi yang kurang baik dapat menyebabkan air bak toilet dapat ditumbuhi oleh jamur. Candida albicans adalah jamur komensal dan flora normal yang berperan dalam keseimbangan mikroorganisme dalam tubuh kita, beberapa faktor predisposisi dapat mengubah sifat saprofit Candida albicans menjadi patogen, antara lain: Diabetes Mellitus, penyalahgunaan antibiotik, penggunaan obat kartiokostreoid dan sitostatik, kehamilan, penggunaan pil anti hamil dan kelembapan yang tinggi. Kontaminasi jamur Candida albicans pada air bak toilet dapat disebabkan dari berbagai sumber, diantaranya adalah kontaminasi dari sumber air, kontaminasi dari pengunjung, dan lingkungan sekitar toilet. Jenis penelitian yang digunakan adalah penelitian studi literatur dengan mencari referensi teori yang relevan dengan kasus atau permasalahan yang dirtemukan. Berdasarkan hasil studi literatur 7 jurnal/KTI/skripsi dari 101 sampel, 31 sampel diantaranya positif Candida albicans sehingga dapat diambil kesimpulan terdapat $29.99 \%$ toilet dengan air bak yang mengandung Candida albicans.
\end{abstract}

Kata Kunci: Candida albicans, air bak toilet.

\section{PENDAHULUAN}

Sebuah bangunan pastilah memiliki area yang harus digunakan secara bersamasama. Toilet umum merupakan tempat dimana seseorang diharuskan ataupun dipaksa untuk bebagi dan secara bergantian dalam penggunaannya. Dalam prosesnya penggunaan toilet secara bergantian berpengaruh terhadap kesehatan para pengguna toilet tersebut. Kesehatan pengguna dapat dipengaruhi oleh keadaan bangunan, perlengkapan dan peralatan dari toilet dan para pengguna toilet tersebut. Tidak sedikit dari perilaku para pengguna toilet yang tidak memperhatikan kepentingan dan hak dari pengguna lain, yang seharusnya saling menjaga kepentingan dan kewajiban bersama (Widhianto, 2018).

Toilet adalah sarana sanitasi yang paling vital. Kebersihan toilet dapat dijadikan ukuran terhadap kualitas manajemen sanitasi di suatu tempat. Parameter kebersihan toilet yang paling utama dapat dilihat dari frekuensi menguras atau pembersihan air baknya. Sanitasi yang kurang baik dapat menyebabkan air bak toilet dapat ditumbuhi oleh jamur (Jauriah dan Maritza, 2019).

Jamur merupakan salah satu penyebab penyakit infeksi terutama di negara-negara tropis. Penyakit yang disebabkan oleh jamur disebut mikosis. Mikosis yang mempunyai insiden paling tinggi adalah dermatofitosis dan kadidiasis. Kandidiasis ialah infeksi jamur yang menyerang kulit, kuku, selaput lendir dan alat dalam yang disebabkan oleh berbagai spesies Candida. Penyebab terbanyak kandidiasis adalah Candida albicans spesies dengan patogenitas paling tinggi (Rani dan Wantini, 2016).

Candida albicans adalah jamur komensal dan flora normal yang berperan dalam keseimbangan mikroorganisme dalam 
tubuh kita, serta ditemukan dalam traktus intestinal, kulit, dan traktus genita urinaria (Indrayanti dan Sari, 2018).

Beberapa faktor predisposisi dapat mengubah sifat saprofit Candida albicans menjadi patogen, antara lain: Diabetes Mellitus, penyalahgunaan antibiotik, penggunaan obat kartiokostreoid dan sitostatik, kehamilan, penggunaan pil anti hamil dan kelembapan yang tinggi (Rani dan Wantini 2016).

Kandidiasis juga sering didapatkan pada orang yang memakai fasilitas umum secara bersama-sama sehingga penyakitnya disebut dengan Water Bath Dermatitis. Fasilitas umum yang digunakan bersamasama memiliki potensi untuk tumbuhnya jamur misalnya, toilet. Penggunaan toilet secara bersama-sama dapat menyebabkan kondisi toilet jadi kurang terawat, karena belum tentu semua orang yang menggunakan toilet tersebut mempunyai kebiasaan hygiene yang baik (Indrayanti dan Sari, 2018).

Berdasarkan penelitian tentang identifikasi jamur Candida albicans pada air bak toilet umum di pasar tradisional kota Pekanbaru yang berjumlah 15 sampel, ada 8 sampel yang positif terkontaminasi jamur Candida albicans dan ditemukan jamur spesies lain seperti Aspergillus, Trichopython dan Mucor. Beberapa faktor yang dapat mempengaruhi pertumbuhan jamur Candida albicans pada nutrien agar diantaranya adalah kontaminasi pada air. Kontaminasi jamur Candida albicans pada air bak toilet dapat disebabkan dari berbagai sumber, diantaranya adalah kontaminasi dari sumber air, kontaminasi dari pengunjung, dan lingkungan sekitar toilet (Juariah dan Maritza, 2019).

Penggunaan toilet umum sudah banyak digunakan terutama di tempattempat yang besar. Dengan fakta tersebut maka penelitian ini berfokus pada air bak toilet. Berdasarkan uraian Latar Belakang diatas maka calon peneliti mengangkat judul Identifikasi Jamur Candida albicans pada air bak toilet.

\section{METODE PENELITIAN}

Penelitian ini merupakan studi literature dengan menggunakan sumber data primer yaitu instrument online seperti jurnal dan artikel.

\section{HASIL PENELITIAN}

Berdasarkan hasil dari beberapa penelitian terdapat persamaan dan perbedaan dari beberapa penelitian. Literature diambil dari tahun 2017-2019 yang relevan dengan hasil data sebagai berikut

\section{Tabel 1. Sintesa hasil penilitian}

\begin{tabular}{|c|c|c|c|}
\hline $\begin{array}{c}\text { Nama jurnal / No. } \\
\text { volume / tahun / } \\
\text { penulis }\end{array}$ & $\begin{array}{c}\text { Judul } \\
\text { Penelitian }\end{array}$ & $\begin{array}{c}\text { Desain } \\
\text { Penelitian }\end{array}$ & Hasil Penelitian \\
\hline $\begin{array}{l}\text { Jurnal Kesehatan } \\
\text { Perintis (Perintis's } \\
\text { Health Journal)/ } \\
\text { Volume 5. Nomor } \\
\text { 2/ 2018/ Sri } \\
\text { Indrayati dan } \\
\text { Reszki Intan Sari }\end{array}$ & $\begin{array}{l}\text { Gambaran } \\
\text { Candida } \\
\text { albicans pada } \\
\text { Bak } \\
\text { Penampung } \\
\text { Air di Toilet } \\
\text { SDN 17 Batu } \\
\text { Banyak } \\
\text { Kabupaten } \\
\text { Solok }\end{array}$ & $\begin{array}{l}\text { Metode } \\
\text { Deskriptif }\end{array}$ & $\begin{array}{l}\text { Hasil Penelitian menunjukkan } \\
\text { bahwa sebanyak } 3 \text { sampel air bak } \\
\text { penampung yang diperiksa } \\
\text { didapatkan semua menunjukkan } \\
\text { hasil negatif mengandung jamur } \\
\text { Candida albicans }\end{array}$ \\
\hline
\end{tabular}




\begin{tabular}{|c|c|c|c|}
\hline $\begin{array}{l}\text { Prosiding Seminar } \\
\text { Nasional Sains/ } \\
\text { 2018/ Endrik } \\
\text { Asmarani, Durroh } \\
\text { Humairoh, Deby } \\
\text { Kurniawati }\end{array}$ & $\begin{array}{l}\text { Identifikasi } \\
\text { Jamur } \\
\text { Candida sp. } \\
\text { Dalam Air } \\
\text { Bak Toilet } \\
\text { pada tempat } \\
\text { Wisata di } \\
\text { Wilayah Kota } \\
\text { Kediri dengan } \\
\text { Metode } \\
\text { Centrifugasi }\end{array}$ & $\begin{array}{l}\text { Survey } \\
\text { deskriptif }\end{array}$ & $\begin{array}{l}\text { Berdasakan dari hasil penelitian } \\
\text { dari } 45 \text { sampel didapatkan } 2 \\
\text { sampel positif mengandung } \\
\text { Candida albicans dengan } \\
\text { persentase } 4.44 \% \text { dan } 43 \text { sampel } \\
\text { tidak mengandung Candida } \\
\text { albicans dengan persentase } \\
95.56 \%\end{array}$ \\
\hline $\begin{array}{l}\text { Jurnal } \\
\text { ERGASTERIO/ } \\
\text { Volume 06, Nomor } \\
\text { 01/ September 2018 } \\
\text { - Februari 2019/ } \\
\text { Siti Jubaidah, } \\
\text { Rifqoh, Dian } \\
\text { Nurmansyah }\end{array}$ & $\begin{array}{l}\text { Gambaran } \\
\text { Candida } \\
\text { albicans pada } \\
\text { Air Bak Toilet } \\
\text { Masjid di } \\
\text { Martapura } \\
\text { Lama } \\
\text { kabupaten } \\
\text { Banjar 2015 }\end{array}$ & $\begin{array}{l}\text { Survey } \\
\text { deskriptif }\end{array}$ & $\begin{array}{l}\text { Hasil penelitian menunjjukan } \\
\text { bahwa dari } 7 \text { sampel air bak toilet } \\
\text { masjid yang diperiksa, } 5 \text { bak toilet } \\
(71 \%) \text { diantaranya mengandung } \\
\text { jamur Candida albicans dan } 2 \text { bak } \\
\text { toilet ( } 21 \%) \text { tidak mengandung } \\
\text { jamur Candida albicans. }\end{array}$ \\
\hline $\begin{array}{l}\text { GEMA Lingkungan } \\
\text { Kesehatan/ Volume } \\
\text { 17, Nomor 1/ } \\
\text { Januari 2019/ Rendi } \\
\text { Aditya Pambudi, } \\
\text { Bambang Sunarko, } \\
\text { Rusmiati }\end{array}$ & $\begin{array}{l}\text { Keberadaan } \\
\text { Jamur } \\
\text { Candida } \\
\text { albicans } \\
\text { Fasilitas } \\
\text { Sanitasi Toilet } \\
\text { di SPBU }\end{array}$ & $\begin{array}{l}\text { Metode } \\
\text { Deskriptif }\end{array}$ & $\begin{array}{l}\text { Hasil penelitian } 6 \text { toilet SPBU } \\
\text { menunjukkan hasil positif } \\
\text { Candida albicans pada semua } \\
\text { toilet. }\end{array}$ \\
\hline $\begin{array}{l}\text { JOPS (Journal of } \\
\text { Pharmacy and } \\
\text { Science)/ Volume 3, } \\
\text { Nomor 1/ Desember } \\
\text { 2019/ Siti Juariah, } \\
\text { Nabila Maritza }\end{array}$ & $\begin{array}{l}\text { Identifikasi } \\
\text { Jamur } \\
\text { Candida } \\
\text { albicans pada } \\
\text { Air Bak Toilet } \\
\text { Umum di } \\
\text { Pasar } \\
\text { Tradisional } \\
\text { Kota } \\
\text { Pekanbaru }\end{array}$ & $\begin{array}{l}\text { Metode } \\
\text { Experimental }\end{array}$ & $\begin{array}{l}\text { Berdasarkan hasil pemeriksaan } \\
\text { dari } 8 \text { pasar yang ada dikota } \\
\text { Pekanbaru, ada } 5 \text { pasar yang } \\
\text { ditemukan positif terkontaminasi } \\
\text { jamur Candida albicans, dan } 3 \\
\text { pasar lainnya terkontaminasi } \\
\text { jamur spesies lain, dari } 15 \text { sampel } \\
\text { air bak toilet yang ada di pasar } \\
\text { tradisional kota } \\
\text { Pekanbaru ditemukan } 8 \text { sampel } \\
\text { yang terkontaminasi jamur } \\
\text { Candida albicans }\end{array}$ \\
\hline $\begin{array}{l}\text { KTI/ 2017/ Eka } \\
\text { Mujayana }\end{array}$ & $\begin{array}{l}\text { Identifikasi } \\
\text { Cemaran } \\
\text { Jamur } \\
\text { Candida } \\
\text { albicans pada } \\
\text { Air Bak Toilet }\end{array}$ & $\begin{array}{l}\text { Metode } \\
\text { Deskriptif }\end{array}$ & $\begin{array}{l}\text { Berdasarkan hasil pemeriksaan } \\
\text { pada Identifikasi cemaran jamur } \\
\text { Candida albicans pada air bak } \\
\text { toilet di Ruang Bersalin RSUD } \\
\text { Jombang negatif Candida albicans } \\
\text { sejumlah } 8(88,89 \%) \text { dan positif } \\
\text { Candida albicans sejumlah } 1\end{array}$ \\
\hline
\end{tabular}


di Ruang

Bersalin

$\begin{array}{lll}\text { Jurnal GLOBAL } & \text { Analisis } & \text { Metode } \\ \text { HEALTH } & \text { Kandungan } & \text { Analitik } \\ \text { SCIENCE/ Volume } & \text { Jamur } & \\ \text { 2/ Issue 4/ } & \text { Candida } & \\ \text { Desember 2017/ } & \text { albicans } & \\ \text { Juwitha Esthi } & \text { terhadap } & \\ \text { Utami, Rusmiati, } & \text { Sanitasi Toilet } & \\ \text { Fitri Rokhmalia, } & \text { Umum di } & \\ \text { Suprijandani } & \text { Pasar Kota } & \\ & \text { Bojonegoro } & \end{array}$

$(11,11 \%)$ dari total 9 sampel air bak toilet \begin{tabular}{llr}
\multicolumn{2}{c}{ Candida albicans merupakan } \\
spesies jamur dari keluarga
\end{tabular}

Saccharomycetaceae dan organisme flora normal yang berperan dalam keseimbangan tubuh. Candida albicans memiliki sifat patogen yang dapat menyebabkan infeksi opotunistik disebut dengan kandidiasis. Kandidiasis dapat menyerang kulit, kuku, rambut, mukosa mulut dan organ dalam manusia.

Identifikasi Candida albicans pada air bak toilet dapat dilakukan dengan cara sederhana menggunakan mikroskop yaitu pemeriksaan langsung dengan $\mathrm{KOH} 10 \%$ maka akan tampak hifa maupun spora sedangkan menggunakan pewarnaan gram maka tunas atau budding yeast akan tampak berwarna ungu. Kemudian dapat dilakukan pemeriksaan dengan kultur pada media Sabouraud dextrose agar (SDA) maka akan nampak koloni berwana putih, dengan permukaan licin, menonjol serta memiliki bau khas (yeast odor). Uji biokimia yaitu glukosa, maltosa, laktosa, dan sukrosa apabila Candida albicans memfermentasi glukosa, maltosa, laktosa dan sukrosa menjadi asam dan gas maka dinyatakan positif, fermentasi dapat ditandai dengan perubahan warna media dari ungu menjadi kuning sedangkan pembentukan gas ditandai adanya gelembung gas pada tabung durham.

Pada penelitian ini menggunakan metode studi literatur dengan judul identifikasi Candida albicans pada air bak toilet. Berdasarkan hasil studi literatur diperoleh 7 jurnal/KTI/skripsi/prosiding yang berkaitan dengan penelitian yaitu penelitian yang telah dilakukan oleh Sri Indrayati dan Reszki Intan Sari (2018) dengan judul "Gambaran Candida albicans pada bak penampung air di toilet SDN 17 Batu Banyak kabupaten Solok" yang merupakan penelitian dengan desain deskriptif dengan 3 sampel bak penampung air didapatkan hasil semua bak penampung negatif mengandung Candida albicans.

Penelitian yang dilakukan oleh Endrik Asmarani et al (2018) yang berjudul "Identifikasi jamur Candida $s p$ dalam air bak toilet pada tempat wisata di wilayah kota Kediri dengan metode 
centrifugasi" dari 45 sampel didapatkan hasil dengan 2 (4.44\%) sampel positif mengadung Candida albicans dan 43 (95.56\%) sampel lainnya tidak mengandung Candida albicans. Sampel air yang mengandung Candida sp. dapat disebabkan tidak dilakukannya pembersihan toilet dan pembersihan bak air secara rutin. Lalu penggunaan toilet ditempat wisata berbanding lurus dengan pengunjung yang memiliki latar belakang yang berbeda dan hygine yang berbeda. Toilet umum tempat wisata yang sejuk, lembab, dan tidak adanya tempat sampah juga tidak tersedianya sabun pencuci tangan mengakibatkan jamur Candida $s p$. dapat berrkembang dan hidup dalam air bak toilet

Penelitian selanjutnya dari Siti Jubaidah et al (2019) dengan judul "Gambaran Candida albicans pada air bak toilet masjid di Martapura Lama kabupaten Banjar 2015" Dengan jumlah sampel 7 air bak toilet masjid, 5 bak toilet $(71 \%)$ diantaranya mengadung Candida albicans dan 2 bak toilet (21\%) tidak mengandung Candida albicans. 5 sampel air positif dapat disebabkan dari sumber air yang digunakan yaitu dari air sungai. Air sungai merupakan air yang sangat tercemar dapat diakibatkan dari kotoran seperti lumpur, batang-batang kayu, daun-daun, kotoran industri atau limbah rumah tangga. Selain itu proses pembersihan baik air toilet masjid Martapura Lama kabupaten Banjar hanya dilakukan kurang dari seminggu sekali dan tidak menggunakan cairan desinfektan.

Penelitian yang sama dengan sampel air bak toilet juga dilakukan oleh Siti Juariah dan Nabila Maritza (2019) dengan judul "Identifikasi jamur Candida albicans pada air bak toilet umum di Pasar Tradisional kota Pekanbaru" dengan sampel dari 8 pasar yang ada dikota Pekanbaru, 5 pasar ditemukan positif terkontaminasi Candida albicans dan 3 pasar lainnya terkontaminasi oleh spesies jamur lain. Dari 5 pasar tersebut diambil sampel 15 bak air toilet ditemukan 8 sampel yang terkontaminasi oleh Candida albicans.

Penelitian yang dilakukan Rendi Aditya Pambudi et al (2019) dengan judul "Keberadaan jamur Candida albicans fasilitas sanitasi toilet di SPBU dari 6 toilet semuanya menunjukaan hasil positif Candida albicans.

Kemudian penelitian selanjutnya yang dilakukan oleh Eka Mujayana pada tahun 2017 dengan judul "Identifikasi cemaran jamur Candida albicans pada air bak toilet di ruang bersalin", 8 sampel (88.89\%) negatif Candida albicans dan 1 (11.11\%) positif Candida albicans dari total 9 sampel. 1 sampel positif disebabkan dari proses pembersihan bak air toilet yang belum menggunakan cairan pembersih sesuai dengan aturan yang ada

Penelitian dengan judul "Analisis Kandungan Jamur Candida albicans terhadap Sanitasi Toilet Umum di Pasar Kota Bojonegoro oleh Juwitha Esthi Utami et al (2017) bahwa dari 16 toilet di dapatkan 10 toilet negatif mengandung Candida albicans 6 toilet positif mengandung Candida albicans kemudian hasil observasi mengenai kualitas bak air toilet di pasar kota Bojonegoro memperoleh kriteria kurang yaitu sebesar $56 \%$ dengan kondisi fisik air tampak kotor, keruh, agak berbau, dan berasa.

Dari berbagai literature yang ditemukan rata rata air bak toilet mengadung Candida albicans dan beberapa oleh jamur jenis lain. Dari 7 literatur yang dilakukan masing-masing peneliti ada 1 penelitian yang negatif Candida albicans dan 6 lainnya positif Candida albicans. Kontaminasi Candida albicans pada air bak toilet dapat disebabkan dari berbagai sumber, 
diantaranya sumber air, kontaminasi dari pengguna dan lingkungan sekitar toilet. Air sebagai keperluan sehari-hari dapat dicemari oleh berbagai macam organisme salah satunya Jamur, jika air telah terkontaminasi oleh jamur maka air tersebut akan menjadi sumber infeksi bagi penggunanya selain itu pengguna toilet yang terinfeksi oleh Candida albicans dapat menyebabkan toilet yang digunakannya akan terkontaminasi apabila terjadi kontak kulit.

Faktor prediposisi berperan dalam meningkatkan pertumbuhan Candida albicans serta memudahkan masuknya jamur ke dalam jaringan tubuh karena adanya perubahan keseimbangan flora normal atau perubahan mekanisme daya tahan tubuh. Blastospora akan berkembang menjadi hifa semu kemudian hifa semu akan menyerang jaringan tubuh, sehingga perusakan jaringan dapat terjadi. Virulensi dapat dilihat dari kemampuan jamur merusak jaringan serta masuk ke dalam jaringan. Enzim-enzim yang berperan sebagai faktor virulensi adalah enzim hidrolitik seperti proteinase, lipase, dan fosfolipase. Faktor kontaminasi jamur Candida albicans adalah air (Mujayana. 2017)

\section{KESIMPULAN DAN SARAN}

Berdasarkan hasil studi literatur dari 7 jurnal/KTI/skripsi/prosiding dari 101 sampel, 31 sampel diantaranya positif Candida albicans sehingga dapat diambil kesimpulan terdapat $29.99 \%$ toilet dengan air bak yang mengandung

Candida albicans. Air bak yang mengandung Candia albicans disebabkan jarangnya pembersihan bak air pada toilet serta tidak menggunakan cairan desinfektan atau cairan pembersih khusus

Perlu dilakukan penelitian lebih lanjut untuk melakukan studi lapangan yang didukung oleh data hasil penelitian sebelumnya serta menambah jumlah sampel yang akan diamati

\section{DAFTAR PUSTAKA}

Anjasriyanti, KN. 2015. Perbedaan Jumlah Germ Pada Berbagai jenis Telur Putih, (Online), (diakses 13 Maret 2020).

Asmarani, E et al. 2018. Identifikasi Jamur Candida sp. dalam Air Bak Toilet pada Tempat Wisata di Wilayah Kota Kediri dengan Metode Centrifugasi. Prosiding Seminar Nasional Sains, Teknologi dan Analisis Ke-1

Indrayanti, S., Sari, RI. 2018. Gambaran Candida albicans pada bak penampung air di toilet SDN 17 Batu Banyak kabupaten Solok. Jurnal Kesehatan Perintis (Perintis's Health Journal). 5(2):134

Indriani, S. 2018. Hubungan Higienitas Vagina, Kadar Gula Darah dan Kadar Hormon Estrogen pada Kejadian Kandidiasis Vaginalis. Tesis diterbitkan Padang :Program Studi S2 Ilmu Kebidanan Pasca Sarjana Fakultas Kedokteran Universitas Andalas Padang.

Jan, A et al. 2018. Modifided Germ Tube Test : A Rapid Test for Differentiation of Candida albicans from Candida dubliniensis. International Journal of Contempory Medical Research. 5(3):C15

Jauriah, S., Maritza, N. 2019. Identifikasi Jamur Candida albicans pada Air Bak Toilet Umum di Pasar Tradisional Kota Pekanbaru. JOPS (Jurnal Of Pharmacy and Science). 3(1):36-39

Khusnul., Muta'aly, SJ. 2018. Identifikasi Jamur Candida albicans pada Karies Gigi Anak di Bawah Umur 10 Tahun Siswa SDN Sariwangi Kabupaten Tasikmalaya. Prosiding 
Seminar Nasional dan Diseminasi Penelitian Kesehatan

Maharani, S. 2012. Pengaruh Pemberian Larutan Ekstrak Siwak (Salvadora persica) pada Berbagai Konsentrasi terhadap Pertumbuhan Candida albicans. Karya Tulis Ilmiah diterbitkan Semarang: Program Studi Sarja Kedokteran Fakultas Kedokteran Universitas Diponegoro.

Martosenjoyo, T. 2016. Budaya Bertoilet : Duduk atau Jongkok?. Jurnal Etnosia. 1(1):44-53.

Mujayana, E. 2107. Identifikasi Cemaran Jamur Candida albicans pada Air Bak Toilet di Ruang Bersalin. Karya Tulis Ilmiah diterbitkan Jombang: Program Studi Diploma DIII Analis Kesehatan Sekolah Tinggi Ilmu Kesehatan Insan Cendekia Medika Jombang.

Mutiawati, VK. 2016. Pemeriksaan Mikrobiologi pada Candida albicans. Jurnal Kedokteran Syiah Kuala. 16(1):55-59.

Pambudi, RA., Sunarko, B., Rusmiati. 2019. Keberadaan jamur Candida albicans Fasilitas Sanitasi Toilet di $S P B U$. Jurnal Kesehatan Lingkungan. 17(1):4.

Rani, TS., Wantini, S. 2016. Gambaran Jamur Candida albicans pada penderita Diabetes Mellitus di RSUD. Jendral Ahmad Yani kota Metro. Jurnal Analis Kesehatan. 5(2):562.

Supriyanto., Kuswiyanto., Nurhayati, E. 2018. Efektivitas Air Perasan Daun
Lidah Buaya (Aloe vera) Terhadap Pertumbuhan Jamur Trichophyton rubrum dengan Metode Dillution Test. Jurnal Laboratorium Khatulistiwa. 2(2):159.

Virgianti, DP., Nurwiansah, R. 2014. Pemeriksaan Kontaminasi Candida albicans pada Air Kolam Renang di Kota Tasikmalaya. Jurnal Kesehatan Bakti Tunas Husada. 11(1):180-181. Widhianto, MA. 2015. Kesehatan pada Toilet Umum berdasarkan Sentuhan Tangan. Prosiding Temu Ilmiah ILPBI. 